\title{
Metaphorical profile of distress in English media discourse
}

\author{
Anna Verbytska \\ Lesya Ukrainka Eastern European National University, Ukraine
}

\begin{abstract}
The current research is directed towards the transition of distress studies in the English speaking culture from the prototype towards the conceptual metaphor approach. It enables the enlightenment of mental images, which underlie distress language usage in modern mass communication. The analysis involves identification of conceptual distress metaphors and metonymies within the image-schematic structure. The study includes a cognitive semantic analysis of linguistic units of the distress lexicon retrieved from the GloWbE, BNC, COCA, English newspapers and media platforms. Figurative language reveals conventional beliefs about distress represented in English media discourse, such as strong associations of emotion with darkness and coldness. Metaphorical mappings contain views about the reasons for distress experience which lie in the loss of balance or inner equilibrium, loss of control, and convictions about the reaction characterizing a person as being weak and brittle. The findings of data analysis are summed up in a metaphorical profile of distress (MPD) which discloses the behavioural patterns (communicative behaviour, adequacy/inadequacy of behaviour, ability to socialize) and physical effects including health issues.
\end{abstract}

\section{Key words}

metaphorical profile, distress, media discourse, metaphor, metonymy, emotion concept

\section{Introduction}

The language of emotions presupposes a high level of figurativeness which is fundamentally rendered through metaphors and metonymies. As claimed by scientists, metaphoric and metonymic concepts structure our language, thoughts, attitudes, and actions (Lakoff and Johnson, 1980). We experience feelings, store them in our minds in the form of a concept, and express them in language through conceptual emotion metaphors and metonymies. The projections of our knowledge about the phenomena of the external and internal worlds (physical objects, experiences and emotions) are formed by conventional phrases. These phrases represent "the established semantic interpretations of words", and are realized in language in a creative way to think about the target domains (Handl, 2011, p. 25). Kövecses,
Palmer and Dirven brought their survey of metaphor and metonymy research into a broader scientific context and applied it to emotion language:

If one holds the view that emotion language is governed by cognitive models, including conceptual metaphors and metonymies, then figurative language becomes important, if not central to the semantic study of emotion language. (Kövecses et al., 2003, p. 138)

Metaphor and affective language were studied through the prototype (Ortony, et al., 1988) and the social-constructionist approaches (Lutz, 1988). The advocates of the former think of emotion words as culture-free and universal. The representatives of the latter think of them as "highly culture-specific constructs built 
up by people's social and geophysical context and conditions" (Lutz, 1988 cited in Dirven and Pörings, 2003, p. 12) and thus nonuniversal. Within the two-domain approach, linguists go beyond the two aforementioned contradictory views and suggest an interrelation between physiological motivation and socialcultural substance in production of emotion concepts (Kövecses, 2000, p. 14). Linguists conducted a thorough analysis of metaphoric and metonymic conceptualizations for a range of emotion categories such as happiness, fear, anger, love, and others (Kövecses, 2000). Distress is proved to be a part of the motivational system of a human being. It is referred to as one of the basic emotions - an inborn neural programme which empowers a human with energy and influences the cognitive and behavioural sphere (Tomkins, 1984; Izard, 1991). Izard claimed that distressanguish is one of 10 fundamental facial emotional expressions of infants. Ortony et al. study distress as an emotion type, specifying it as a negative reaction elicited by an undesirable event which an individual is displeased about (Ortony et al., 1988, p. 87). Consequently, distress has expressive (bodily experience) and causal universal aspects of conceptualization. Distress is a complex emotion arising from "appraisals that necessarily have propositional content, usually recognized consciously, that concerns one's self, which embodies one's ideals" (Oatley and Johnson-Laird, 2013, p. 2 ). In this line, the complexity of distress presupposes a dependence on cultural differences realized in language. Little attention has been paid to the linguistic investigation of distress. The necessity of its study is apparent and urgent, however, because the person in distress "views the world through a distorting lens" (Stott, et al., 2010, p. 5). This perverted reality is depicted in media by the extensive usage of language denoting negative experience.

Past research on distress in language was partly conducted by Wierzbicka (1999) who analysed emotion terms, and distress in particular, within the theory of semantic universals, by applying her natural semantic metalanguage approach (NSM). Culture-specific emotion concepts were analysed via the innately intelligible universal concepts / semantic primitives such as bad and good or know and want. The scholar differentiated the concept of distress from other English-specific emotion concepts by discovering its cognitive scenario on the basis of the category of time. The findings of her work throw light on the distinguishing features of distress from other emotion concepts, such as present orientation, personal character, and an active and less resigned attitude (Wierzbicka, 1999, p. 64). The investigation does not touch upon the metaphorical aspect, however. It provides information about the prototypical component of the concept DISTRESS and serves as a starting point for further research on its figurative aspect in the current paper.

Distress has been studied through the cognitive linguistic approach of Lakoff, Johnson and Kövecses by King (2010). The work profoundly investigates the conceptual metaphors used by Hebrew speakers to think about distressing experiences through embodied experience. The main findings provide the manifestations of the image schemas for distress (VERTICALITY, CONSTRAINT, and FORCE) and primary metaphors (DARKNESS and BAD TASTE) in biblical texts and reflect the prototypical conceptualization of this negative experience across cultures, namely Hebrew and English. In the current paper, we follow the pattern of how to apply this methodology to reconstruct knowledge about distress experience in the English culture.

Taking into account this background, the purpose of this research is to investigate beliefs about distress experience implied in a message or imposed on the reader in English media through the system of conventional figurative language. The core research problem in the study is addressed to modelling the MPD in English media discourse - the set of metaphorical mappings characterizing distress as emotion and its experiencer, which are figuratively represented in context. The specific research objectives are as follows: 1) to systematize distress metaphors according to image schemas; 2) to discover the semantic underpinnings of distress conceptualizations grounded in schemas in order to determine the portrait of a distress experiencer and the emotion itself; 3) to establish the metonymic basis for metaphorical mappings of distress by investigating its metonymic mappings. 
The findings of this research are expected to highlight the unaddressed issues of the metaphorical representation of the emotion concept DISTRESS in English and move forward the understanding of the affective potential of figurative emotion language in English media discourse. The modelled profile will contribute to the theory of linguistics of emotions from the cognitive linguistic perspective. Our findings may contribute to comparative studies of emotion concepts across cultures.

\section{Data source and methodology}

In our current research we applied a method based on Conceptual Metaphor Theory (Lakoff and Johnson, 1980) and Image Schema Theory Uohnson, 1987; Hampe, 2005). Fragments of media discourse were collected from quality English newspapers such as the Guardian, Express, Observer, Independent, Telegraph, BBC News, and the American news and opinion website Salon. The corpora search yielded 2980 tokens from the sections "Newspaper" and "Magazine" in the Corpus of Global Web-Based English (GloWbE), the Corpus of Contemporary American English (COCA), and the British National Corpus (BNC). Corpus- and discourse-based research of the concept DISTRESS involved occurrences of the distress lexeme in various lexicogrammatical constructions which formed metaphorical expressions. We included an analysis of metaphors containing a range of lexemes which constitute the nucleus of the lexical / semantic field of the concept DISTRESS. These are the ones which define distress in the dictionaries and have the highest frequency in the list of synonyms (286) compiled from COBUILD, OALD, MED, Merriam-Webster Thesaurus, and Wordnet: pain (occured 6 times), suffering (5), distress (4), sadness (4), anxiety (4).

Following Langacker, Croft distinguishes base and profile within a concept (Croft, 2003, p. 166). The base/domain is defined as that aspect of knowledge which compulsorily takes part in conceptualizing the profile. In the paper the first notion pertains to the prototypical features of the emotion concept and the second one is referred to the distinctive features stratified upon the base by the cultural origin of the concept and its contextual usage. The metaphorical profile approach (MPA) is a corpus-linguistic method adopted by scholars (Stefanowitsch, 2004; Ogarkova and Soriano, 2015) to conduct studies on emotion concepts. Within the MPA, a concept is characterized by metaphorical patterns / "regular lexico-grammatical constructions" entertained by the lexemes naming that emotion.

The development of the MPD involved the two-domain approach (TDA) for data evaluation, grounded in Kövecses, Croft, Barcelona, etc., who compared the Lakovian approach to emotion theories. In Croft's view, TDA is explained as the "conceptualization of one domain in terms of the structure of another independent domain" (Croft, 2003 cited in Dirven, p. 14). A conceptual source domain (SD) is mapped onto a conceptual target domain (TD). The SD for emotion concepts is a physical domain (e.g. "LOVE IS FIRE") and/or a physiological domain (e.g. "DROP IN BODY TEMPERATURE STANDS FOR FEAR"). Metaphor is a cross-domain mapping. In our study conceptual mappings were formed following the formula CONCEPTUAL DOMAIN A (target domain) IS CONCEPTUAL DOMAIN B (source domain). We conducted a cognitive semantics analysis of the linguistic units forming metaphorical expressions to create the MPD. The process unfolded in three steps: 1) identification of the image schemas framing the mappings; 2) identification of the physical domains, and 3) identification of the physiological domains for the target domain DISTRESS. We discovered the domain concepts by analysing (with the help of explanatory dictionaries) the conceptual / semantic space that represents word meaning in context. Within the frameworks of cognitive linguistics, semantic space involves the whole of common sense experience and world knowledge structured in domains (Dirven, 2003, p. 13). Thus, semantic space characterizes a source domain. The sum of source domains constitutes the range of distress metaphors which by nature belong to the ontological, orientational, and structural conceptual metaphors in the system of conventional figurative language. Conventional metaphors were analysed in terms of "skeletal" image schemas. The image schemas "emerge out of the spatial and force-dynamic sense and are abstracted from rich and detailed experience" (Dancygier and Sweetser, 
2014, p. 23). They structure more complex concepts which are already linked to the experience. Physiological domains are defined by the bodily symptoms of distress experience fixed in language. The metonymic basis for the metaphorical mappings was established by using "stand-for" relationships.

\section{What is distress?}

Distress is regarded by pathologist Selye (1974) as a psychological state of emotional tension characterized by a high degree of expressiveness, intensity, and duration. According to Tomkins, distress is a bodily and mental suffering (Tomkins, 1963 cited in Izard, 1991, p. 193). Distress is also defined as mental "pain" (Minsky, 2006, p. 73). We hold the view that distress is a hybrid/complex emotion strongly connected with human cognition and triggered by situations and their evaluation. It modifies communicative behaviour; it is represented in the consciousness of English by a cognitive scenario; and it is verbally realized in media discourse. The lexeme distress belongs to the category of descriptive emotion words. Distress is defined as a feeling of extreme unhappiness (LDOCE); suffering that affects the mind or body (Merriam-Webster's Learner's Dictionary); great physical or mental pain (LDOCE, Collins English Dictionary). Distress also implies mental or physical strain imposed by pain, trouble, worry or the like and usually suggests a state or situation that can be relieved (Collins English Dictionary). The philosopher Marcus Aurelius, a practitioner of the modern understanding of what constitutes ancient Stoicism, argues in "The Meditations" that "If you are distressed by anything external, the pain is not due to the thing itself, but to your estimate of it; and this you have the power to revoke at any moment." Hence, distress is evoked by some inner or external stimuli which are valued as negative and, therefore, cause intense feelings of worry, suffering, pain, and overall unhappiness. Oliver Goldsmith, the Irish novelist, playwright and poet, assumes that "The mind is ever ingenious in making its own distress". Thus, the state of mind is a source for the emotional state to become negative. Although, overcoming distress fulfils an important adaptive function and changes the way a person thinks.
But then, to make any further gain, we'll have to endure at least some distress. So, while pleasure helps us learn easy things, we must learn to "enjoy" some suffering when it comes to learning things that need larger-scale changes in how we think. (Minsky, 2006, p. 213)

Physiological effects may vary from a loss of energy to piercing laments. Responses of the body to the feeling are rendered metonymically and form the basis for elaborate metaphors.

\section{Conventional distress metaphor mappings}

"Mappings are highly conventional ways of thinking [,] which are realized in language in many different ways" (Handl, 2011, p. 28). Distress metaphor mappings are organized according to the classification of conventional metaphors by Lakoff and Johnson into orientational, ontological, and structural ones (1980). An imageschematic structure is included in a mapping scope. It defines whether correspondences for the mapping from a source concept onto a chosen target concept are eligible (Ungerer and Schmid, 2006, pp. 119-120; Handl, 2011, p. 31). Image schemas are embodied preconceptual structures which capture the perceptual experience and that of bodily movements (Hampe, 2005, p. 1). Lakoff and Turner (1989) state that all mental images possess an imageschematic structure. Conventional metaphors, framed by image schemas, define a prototypical scenario giving us an opportunity to create the metaphorical profile of distress.

\subsection{Orientational distress metaphors} Lakoff argues that "orientational metaphors give a concept a spatial orientation" (Lakoff, 1980, p. 15). We include in this group the distress metaphors framed by the Verticality, the Centre-Periphery, and the Blockage / Constraint Schemas which belong to the group of spatial image schemas (Krzeszowski, 1993). Casasanto and Dijkstra (2010) investigated the existence of the cognitive connection between emotion and verticality. For instance, the conceptual metaphor SAD IS NARROW has a physical correlation with a smile, or in this particular case, with the absence of a 
smile. The conceptual metaphor SAD IS DOWN represents a typical posture in distress with a hanging or bending down body (Lakoff and Johnson, 1980, p. 16, p. 19). A downward orientation of sadness in English is highly conventional and thoroughly studied by Lakoff and Johnson (1980), Barcelona (1986). It is mapped as being low and down. As stated by Lakoff and Johnson, the only adequate way of comprehending and representing a metaphor goes through the experiential basis (Lakoff and Johnson, 1980, p. 20).

On the basis of the Verticality Schema the emotional state of distress is conceptualized as BEING IN DISTRESS IS BEING DOWN:

(1) $<\ldots>$ standing on the precipice of distress (GloWbE); she found not only low sexual desire but low distress about it (GloWbE);

(2) Attack Svetlana was in deep distress before the bombs exploded (BNC).

The correspondences for the aforementioned conceptual metaphor represent a perception of the experience of distress as going far below the top or the surface, below the usual height. Furthermore, enduring distress presupposes danger. This aspect is deduced from the semantics of the prepositional phrase on the precipice of that possesses the meaning of a dangerous situation in which something very bad could happen. In the following fragment 3 the brink is related to being down by its meaning of the edge at the top of a steep place from which one can easily go down. The word also denotes the threshold of danger.

(3) The tears fall constantly, but, if she was mad with grief back then, she appears to have pulled back a little from the brink (The Independent, 14 June 2009)

The next target text evokes two conceptual metaphors: BEING IN DISTRESS IS FALLING DOWN as an effect of emotional experience and EXPERIENCING DISTRESS IS BEING WEAK as its result.

(4) Today, Bousignac, $\langle\ldots>$, feels like the whole world is again collapsing around her. 'I don't know if I will ever overcome this. The pain is never-ending. 〈...>,' a distressed Bousignac said (The Guardian, December 02, 2014).

The lexeme collapse contains the following relevant underpinnings in its semantics: firstly, if a building collapses it falls down suddenly; secondly, the reason for falling down is a weak or damaged structure (LDOCE).

With respect to the centre-periphery type of organization of concepts (the Centre-Periphery Schema), the metaphor BEING IN DISTRESS IS BEING IN THE CENTRE is deduced from the following fragments:

(5) Love for his son has kept him going amidst the grief (BNC);

(6) In the midst of the nation's grief' (BNC);

(7) The Muslim tradition spoke to her again at a time of distress in her life, after the death of her mother. 'I was in the midst of a personal crisis, along with my mom's death, $<\ldots>$.' (COCA).

It displays the viewing of one in distress as being surrounded by it or being put into a container with distress.

The Blockage / Constraint Schema belongs to the spatial motion group (Johnson, 1987, p. 45). According to Talmy's scenario, an antagonist, because of its strength, blocks the motion of the agonist. Hence, fragment 8 activates the conceptual metaphor DISTRESS IS HINDRANCE:

(8) The Muslim tradition spoke to her again at a time of distress in her life, after the death of her mother. ' $<\ldots . .>$ I really felt like I was up against a wall <... >. ' (COCA)

The metaphor reveals that undergoing distress makes it arduous for the experiencer to fulfil activities and blocks his or her way out.

\subsection{Ontological distress metaphors}

Daily interaction with physical objects gives rise to various ontological metaphors, so that our emotions can be perceived as entities and substances 
(Lakoff and Johnson, 1980, p. 25). It allows us to reason/judge/explain them by their quantitative characteristics. Quantification of a distress experience can show a high level of strain: made even more grievous; such a degree of distress; an unacceptable degree of distress; as grief grows; he was in a huge amount of pain, or a lower level of tension depending on the situation: in "very little distress"; your distress will be less; shared a little of his distress. Qualitative characteristics show the depth of suffering: to ameliorate intolerable pain or distress; it will cause enormous distress; distress is being made worse; the suffering he went through was appalling (BNC); unimaginable suffering.

Within the Container Schema we have the ontological metaphor mapping DISTRESS IS FLUID IN A CONTAINER as shown in the fragment:

(9) Family's outpouring of grief (Express, 5 January 2014).

As well as for this very prototypical mapping, fragment 10 reveals the conceptual metaphor DISTRESS IS AN OBJECT IN A CONTAINER:

(10) Let her grief come out now (BNC). Conceiving of distress as an object, we give it the status of a thing, thus conceptualizing it as "our possession" (term by Kövecses, 2002) and referring to it as her grief; personal distress; my distress; his distress, e.g.:

(11) 'A passerby $<\ldots>$ quickly realized his distress' (GloWbE).

The metaphorical mapping DISTRESS IS A PHYSICAL OBJECT is shown by the correspondences in the fragments:

(12) Church, like therapy, is a countercultural space where people are given permission to bring distress (The Guardian, Friday 3 August 2012);

(13) If you transgress, there will be distress, and Rome can hand out the distress better than anyone (GloWbE); Later he put aside his grief (BNC);
(14) Cole's friend shared a little of his distress over the death of Princess Diana (GloWbE).

The mapping displays the imposition of natural boundaries of physical objects onto the abstract experience of distress to find ways of overcoming, alleviating or outpouring/releasing it.

The BRITTLE OBJECT metaphor reveals psychological strength or weakness while experiencing distress. Belonging to the set of ontological metaphors, it represents pervasive, natural and, thus, highly conventional descriptions of phenomena in our thought process (Lakoff and Johnson, 1980, p. 29). The conceptual metaphor EXPERIENCING DISTRESS IS BEING BRITTLE is activated by the following set of fragments:

(15) They had been pulled apart by the 'horror, distress and pain'. $<\ldots\rangle$ we stand helplessly by and watch the lives of the people we love shattered like glass, knowing we can never put the fragile pieces back together (The Guardian, Wednesday 2 October 2013);

(16) Distressed, crushed. <...>. Two weeks ago, Bousignac's life was further shattered (The Guardian, December 02, 2014);

(17) Mel Greig and Michael Christian told of their distress upon hearing about Saldanha's death. We are shattered (The Guardian, Monday 10 December 2012);

(18) Blackfish focuses on the distress experienced by killer whales <...>. Killer whales have developed complex matriarchal societies $<\ldots>$. When such a family is broken up, the effect is highly stressful (The Observer, Saturday 19 April 2014);

(19) Wracked with grief, Irene breaks down in tears (BNC);

(20) It's an understatement to say that we are completely devastated. Our grief runs deep and the impact of Phillip's loss is enormous 
(The Guardian, Thursday 27 November 2014).

The linguistic units mend, shattered, fragile, wracked, devastated evoke the conceptual underpinnings that expose the weakness and uncertainty of the experiencer who is under pressure and whose life in distress can be easily ruined. The occurrence of the linguistic correspondences for the aforementioned conceptual metaphor is highly systematic, which demonstrates that experiencing distress as being brittle has expanded from the domain of thinking into the domain of speech. Such systematicity shows that mapping is a fixed part of the conceptual system (Lakoff, 1992).

Distress can be viewed not only as substance and an entity but also as a container. Our in-out orientation is mapped onto physical objects and, thus, we perceive them as containers with an inside and an outside (Lakoff and Johnson, 1980 , p. 30). As is claimed, the "container schema involves an Interior, an Exterior, a Barrier" (Dancygier and Sweetser, 2014, p. 23). In this respect, the mapping DISTRESS IS A CONTAINER reflects the prototypical vision of an experience of a negative emotion as being embedded into the container with it. The following fragments serve as an example:

(21) It's a world filled with people in distress, and they are crying out for help (GloWbE);

(22) $<\ldots>$ throwing their lives into grief and chaos (BNC);

(23) Newspapers and journalists serving them should avoid intruding into personal grief (BNC).

(24) Grief is impossible to describe. $<\ldots>$ It is like a cloak, a big, black cloak, smothering me (The Independent, 14 June 2009)

Example (24) motivates an extension / a specific-level mapping DISTRESS IS $A$ CONTAINER WITH A LACK OF AIR. The lexeme smother denotes the symptom of experiencing distress connected with breathing difficulties due to a lack or absence of air that can lead to death. The importance of the metaphor resides in the direct link between psychological suffering and the reaction to it on the physical level. Another specific-level mapping for the container metaphor is DISTRESS IS EMPTINESS / AN EMPTY SPACE generated by the semantics of the lexeme hole which is defined as an empty space in something solid, for example:

(25) A YOUNG woman <...> spoke of her grief after opening his last present to her. Ms White said the apprentice stonemason's death had left 'a hole in her heart that will never mend' (Express, December 26, 2013).

Moreover, in the stated sample the phrase $a$ hole in the heart may be linked to a domain of pathology and has the primary meaning of "a medical condition in which there is an extra opening between the main parts of the heart" (Cambridge Dictionary).

\subsection{Structural distress metaphors}

This type of metaphor enables us to elaborate the DISTRESS concept in considerable detail by using "one highly structured and clearly delineated concept to structure another" (Lakoff and Johnson, 1980, p. 15).

The major / "master" metaphor which forms the superordinate level of the metaphorical emotion system is EMOTIONS ARE FORCES (Kövecses, 2000, p. 61). L. Talmy states that experiencing FORCE is a fundamental human universal (Talmy, 2000, p. 415). The force schema depicts everyday obstacles people should overcome when trying to achieve their goals. The conceptual metaphor DISTRESS IS A PHYSICAL FORCE is prompted by some fragments which extend conceptualization of distress to mechanical and magnetic forces. Fragment (26) has the following metaphorical entailment: experiencing distress produces strong pressure on the experiencer who is mapped onto a container which can be broken or damaged:

(26) 'Every day, I ask God to give me the strength and courage to face another day,' a distressed Bousignac said. <...> 'It crushed me.' (The Guardian, December 02 2014). 
We learn from fragment (27) that it is effortful, or impossible, for an individual who has experienced distress to restore emotional equilibrium and improve health:

(27) 'I will never be able to mend the pain I'm feeling' (Express, 26 December 2013)

In excerpt (28) the semantics of the lexeme muted demonstrate a refraining from speech or incapability of utterance when in distress:

(28) Conservative Democrats reacted with unrestrained glee and liberals with muted distress yesterday to New York Gov. Mario M. Cuomo's announcement' (GloWbE).

In conceptualizing the domain for distress, the fragments (29) and (30) map the experience of distress as a magnetic force attracting other people's empathy towards the experiencer, which is quite conventional: "Emotions often produce empathy in others" (Oatley and JohnsonLaird, 2013, p. 2):

(29) 'His distress only makes him more attractive' (COCA);

(30) I've always been drawn to the distress of Hamlet (GloWbE).

The Balance Schema connects to filledout frames to form a set of mappings of experiencing distress. Here we have a mapping DISTRESS IS IMBALANCE / A LOSS OF EQUILIBRIUM. It is shown by ontological correspondences in the fragments (31) and (32):

(31) Chrysler's stumble from success into distress is nothing new (GloWbE);

(32) Alternating between wide-eyed bewilderment and shaking grief, she endeavours to put her past behind her, and set up home (BNC).

The mapping reveals mental instability through physical experience of almost falling down and small body movements from side to side or up and down (LDOCE). Within this metaphorical mapping a metaphor 'unyogalike distress' occurs in the fragment:
(33) $\langle\ldots\rangle$ they would find themselves less prone to surprise and unyogalike distress (GloWbE).

This metaphor renders a loss of inner peace of mind, and mental and emotional imbalance. The correspondences to the mapping DISTRESS IS INSANITY / A LOSS OF CONTROL explain the inability of people in distress to control their feelings and actions:

(34) There's a wild, frantic sadness to his personality (COCA);

(35) She was mad with grief (The Independent, 14 June 2009)

Lakoff argues that loss of control is connected with the behaviour of a wild animal (Lakoff, 1987, p. 392). Thus, a metaphor DISTRESS IS A WILD ANIMAL with correspondence (36) conceptualizes the physical expression of the inner experience - crying out with a long high sound because of great sadness or pain (LDOCE):

\section{(36) 'Ziba wailed her grief’ (BNC).}

The causes of distress, deduced from the semantics of lexical items such as wound, shellshocked, stricken, can be as follows: an emotional or physical injury, an illness because of the terrible experiences of war, negative affection by trouble, illness, or unhappiness. The corresponding linguistic expression grief stricken for mapping DISTRESS IS AN ILLNESS is conventionally fixed:

(37) I have not been able to sleep or eat. I am totally grief stricken (BNC).

It renders the meaning of being stricken by an unpleasant feeling, an illness or a natural disaster, which severely affects a person (Collins English Dictionary). Conventional figurative expressions and their underlying mappings belong to the realm of human thinking and universal human experiences. The extension of the mentioned mapping is a conceptual metaphor DISTRESS IS AN INFECTION, motivated by a fragment of media discourse: 
(38) There was also evidence of 'emotional contagion', when herd mates matched the behavior and emotional state of the upset individual. In other words, seeing a 'friend' in distress was distressing to the observers (National Geographic, 18 February 2014).

The empirical universal for distress is the feature of infection to spread the disease from one human being or organism to another by close contact. Thus, the significance of this metaphor consists in showing the viral nature of distress. The experiential basis for the metaphor DISTRESS IS AN INJURY is the suffering of some physical injury to the body caused by a weapon. For example:

(39) Death of her father has reopened fresh wounds that may never heal. <...> 'Every day, I ask God to give me the strength and courage to face another day,' a distressed Bousignac said (The Guardian, 2 December 2014).

In fragment (40) distress is also conceptualized as mental illness because of the terrible experiences of war:

(40) 'The policewoman who has been comforting James's parents said his mother Denise was still 'shellshocked' by the loss. She was with the family when they were told that his body had been found and has tried to help them through their grief (BNC).

The metaphor DISTRESS IS LONELINESS gives distress a meaning of inability to socialize with other people. This loneliness while experiencing distress is strongly highlighted in the fragment:

(41) For it's precisely sunny-side-up fascism that forces those of us who walk the black dog into lonely invisibility. The therapist endeavours to help the patient find words that speak of his or her experience and in so doing conveys the sense that emotional distress can be borne and not trivialised (The Guardian, 3 August 2012).
It is constituted by the fixed phrase 'black dog' - a metaphorical representation of melancholy or depression (English Oxford Living Dictionary), used in a new personified context. The corresponding linguistic expression highlights the intensity of loneliness and gives rise to the newly accentuated understanding of a distress experiencer who is not able to see a way out because it is withdrawn from, or out of his / her, sight.

\section{Primary metaphors}

Experientially based metaphors are primary, which means that they display "early and pervasive correlations, often specifically between physical experiential input and subjective judgment or assessment" (Dancygier and Sweetser, 2014 , p. 25, p. 103). Our notion of distress is structured by a set of mappings grounded in basic elements and background conditions. The perceptual basis provides a knowledge structure for the target domain and helps to establish the following metaphorical source domains for distress in English media discourse: absence of light / darkness; and coldness.

The fragment (42) discloses the conceptual metaphor EXPERIENCING DISTRESS IS ABSENCE OF LIGHT IN PART OF THE BODY:

(42) For some people, the only true way to alleviate the black suffering in their heart when someone whose albums they quite liked dies is to sue (The Guardian, Wednesday 12 February 2014).

Culturally, the colour black is associated with mourning, death, grief, unhappiness (Swallow, 2010). Black is defined as the very darkest colour owing to the absence of or complete absorption of light (English Oxford Living Dictionary). In English darkness is perceived through the variation of light up to its total absence. The conceptual metaphor EXPERIENCING DISTRESS IS DARKNESS, retrieved from fragments (43) and (44) is based on the subconscious correlation of LIGHT and GOOD, DARK and BAD which pervades language and visual art (Forceville, 2013): 
(43) And even in the darkest moments of grief, it is possible to glimpse the flickering flame of hope (The Guardian, Saturday 21 December 2013);

(44) 'Our grief runs deep and the impact of Phillip's loss is enormous but nothing compares to the loss felt by those closest to him. <...>. In these darkest of hours cricket puts its collective arms around the Hughes family.' (The Guardian, Thursday 27 November 2014).

The human body perceives sensations of pressure, pain, and temperature (Boundless, 26 May 2016). These senses are integrated into the emotional sphere. The conceptual metaphor EXPERIENCING DISTRESS IS FEELING COLD underlies the fragment (45) and shows the ontological correspondence of a perceptual basis and affective response:

(45) 'And so for us, the news of Verhelst's death sends an inevitable chill to the heart. <...>. Stanley is heartbreakingly correct when he writes that Verhelst 'needed love.' (Salon, Tuesday, Oct $8,2013)$.

Hence, a person assesses the distress with a sensation of cold, with a convulsive shaking of the body caused by narrowing blood vessels, accompanied by muscle tension (The free dictionary - Medical Dictionary).

\section{Image metaphors of distress}

Image / new / "one-shot" metaphors can give new meaning to what is known and believed about experiencing distress in an English speaking culture. Image metaphors show alternative conceptualizations of distress in English media discourse.

Distress is an abstract concept which encompasses a feeling of extreme worry, sadness, or pain (Cambridge Dictionary). Its intensity presupposes a vivid external expression. Fragment (46) evokes a "oneshot" metaphor personified in the following conceptual metaphor BEING IN DISTRESS IS BEING WITHOUT COVERING / UNDISGUISED:

\section{(46) You tread, naked in naked} distress (GloWbE).

The significance of the metaphor lies in depicting one in distress as being vulnerable and unprotected. Furthermore, the metaphor manifests an open and not concealed expression of distress by its experience. In English media discourse distress is also depicted by the metaphor DISTRESS IS A PARODY as something pretentious, unreal which can be copied or acted out as a role. For example:

(47) Curry had said, his voice dripping with mock distress, 'How come you have to make everything racial?' (GloWbE);

(48) Serena threw up her hands in pretend distress (GloWbE).

The functioning of the metaphor DISTRESS IS A PLAY / A PERFORMANCE in newspapers reveals the strategy of the media to present negative emotion as an impressive show for public:

(49) $\langle\ldots\rangle$ rehearse the distress of their ancestors (COCA);

(50) Teenagers are more likely to act out their distress (BNC);

(51) Leigh can be terrific at portraying psychic distress (GloWbE).

\section{Metonymic basis for the metaphors of distress}

Metonymy is more basic than metaphor. It forms the foundation to the whole language system (Handl, 2011, p. 38). Metonymy serves as the motivation to the metaphor and often interacts with it (Grady, 1999; Radden, 2000; Geeraerts, 2002). Metonymic mappings of emotions reflect physiological symptoms/properties through the "stand-for" relation, where one symptom stands for the whole experience. We observe three groups of distress symptoms taken from the article "Common Signs of Distress", that is, physical, emotional / psychological, and behavioural reactions to a specific event. These symptoms correlate with the distinguished metonymical mappings of distress in context. Thus, physical reactions include such symptoms of distress as looking pale, excessive perspiration, breathing difficulties, 
fainting, muscular spasms, obvious intense pain, extreme fatigue, sleep problems, or falling asleep in unexpected circumstances, and continual episodes of illness, colds and flu. We discovered metonymic mappings for distress in English media discourse which correspond to this group of medical symptoms for distress. Thus, in line with the postulated metonymic principle THE PHYSIOLOGICAL AND EXPRESSIVE RESPONSES OF AN EMOTION STAND FOR THE EMOTION (Kövecses, 2000, p. 134), the metonymic mapping FRISSON STANDS FOR DISTRESS corresponds with the physical reaction of muscular spasms, for example:

(52) 'It gives one a frisson of anxiety' (The Guardian, Tuesday 23 December 2014).

Metonymies demonstrating sleep problems are the following: INSOMNIA STANDS FOR DISTRESS, for example:

(53) 'Children held at an immigration detention centre face 'extremely distressing' arrest and transportation procedures. $\langle\ldots\rangle a$ previously happy boy who had become sad, skipped school, lost his appetite, slept poorly (The Guardian, Wednesday 17 February 2010);

NIGHTMARES STAND FOR DISTRESS, for example:

(54) They described children losing weight, having nightmares and crying in their sleep. During her detention, this mother's ten year old son was receiving support from a mental health service, who described him as 'incredibly distressed' about her absence (Open Democracy, 6 May 2013).

The last correspondence evokes another metonymy LOST WEIGHT STANDS FOR DISTRESS linked to the symptom of dramatic weight fluctuation / changes in eating patterns which are a sign of distress according to the health publisher WebMD (Bouchez). Excessive perspiring while experiencing distress is linguistically represented in the metonymy SWEATING STANDS FOR DISTRESS, for example:
(55) 'Families on front line of soldiers' distress. It started with the nightmares - middle-of-the-night eruptions when her fiancé would jolt her awake with his screams, his body drenched in sweat (The Seattle Times, 19 March 2012).

Another metonymy HEAVY BREATH STANDS FOR DISTRESS implies the physical symptom of breathing difficulties:

(56) Ofcom said the younger sister was 'visibly distressed, shouting, crying and breathing heavily' (The Guardian, Monday 14 April 2014).

Such a symptom of distress as extreme fatigue is embodied in discourse through the metonymy RUNNING OUT OF ENERGY STANDS FOR DISTRESS with the correspondence:

(57) $<\ldots>$ crisis counselors from Catholic Charities are on hand to screen for signs of emotional distress and to offer help. 'Do you feel out of energy? (COCA).

The second group of emotional and psychological symptoms involves being tearful, sighing frequently, appearing vague and confused, experiencing high levels of anxiety, panic attacks, irritability, outbursts of anger, displaying agitation, pressured, racing or confused speech patterns, sustained low mood, frequent expressions of negativity. The range of mentioned symptoms occurs in tokens of corpora and media texts in the form of the following metonymic mappings: SCREAMING/CRYING/SHOUTING STANDS FOR DISTRESS:

(58) Samira Zakhi screamed with a mother's piercing wail that filled the largest morgue in Damascus. These were Samira's last distressing moments with her son $<\ldots\rangle$ (BBC News, 13 November 2013);

(59) $1<\ldots>$ her honking a cry of distress' (GloWbE);

(60) TEARS STAND FOR DISTRESS: Wracked with grief, Irene breaks down in tears (BNC); 
(61) NEGATION STANDS FOR DISTRESS: 'I shook my head in distress' (BNC).

The third group of symptoms presupposes changes in behaviour, such as withdrawing socially or verbally, being excessively demanding of others, increases in impulsive behaviour, talk of suicide, violent acts towards self and/or others. Talk of suicide is rendered in media discourse through the metonymy SUICIDAL THOUGHTS STAND FOR DISTRESS with the correspondences:

(62) $\langle\ldots\rangle$ crisis counselors from Catholic Charities are on hand to screen for signs of emotional distress and to offer help. 'Do you have thoughts that you would be better off dead?' (COCA);

(63) For someone in extreme distress, though, how is the option of a razor to the wrist or a gun in the mouth more morally palatable than a physician-administered drug? (Salon, Tuesday 8 Oct 2013).

Some of the symptoms define more than one emotion. Hence, drooping posture, weakness, tears and cries are characteristic of sadness too (Ding, 2012, p. 2386). Sweating, shivering and a low body temperature appear while experiencing fear. However, a distinction can be drawn here. Wierzbicka claims that a sad person tends to accept a bad situation without awareness of its reasons and takes no actions to overcome it (Wierzbicka, 1999, p. 62). On the contrary, an individual in distress actively opposes the situation and wants to do something about it (Wierzbicka, 1999, p. 65). This difference is represented in the physical effects of experiencing these emotions. According to Ekman (1973), sadness is expressed facially only by tears, whereas distress is expressed by loud crying and screaming (Wierzbicka, 1999, p. 64). The theory of conceptual metaphor and metonymy assists in clearing up these differences. The conceptual structure is provided by the correlation of metonymies and metaphors where metonymies inform of a physical basis / bodily symptoms, and metaphors supply the structure with its conceptual potential. Thus, RUNNING OUT OF ENERGY STANDS FOR DISTRESS motivates the metaphor of distress as being weak. The central organ, that is associated with distress in media discourse, is the heart. The metonymic mapping PART FOR WHOLE, particularly, PATHOLOGY FOR DISTRESS, for example, "a hole in one's heart", is combined with the conceptual metaphor DISTRESS IS EMPTINESS. Observing the fragment (64) the metonymic basis for the metaphor DISTRESS IS LOSS OF CONTROL is provided by the physical expression of distress, such as beat their breasts and stamped their feet in grief:

(64) Many of the victims' relatives broke down, fainted or shouted abuse'. While some elderly women beat their breasts, stamped their feet in grief and wept, Chikatilo appeared oblivious to the uproar (BNC).

High expressiveness of distress through screaming, crying, and shouting underlies the metaphor DISTRESS IS A WILD ANIMAL (screamed with a mother's piercing wail). Behavioural symptoms of social or verbal withdrawal serve as a foundation for the distress metaphor DISTRESS IS A LONELINESS.

\section{Conclusions}

The metaphorical profile of distress consists of conventional metaphorical mappings distributed into three groups: orientational (5 metaphorical mappings), ontological (7), and structural metaphors (22). Conventional metaphors are structured within the contours formed by Blockage / Constraint (1 mapping), CentrePeriphery (1 mapping), Verticality (2 mappings), Force (5 mappings), Balance (6 mappings), Container (7 mappings) image schemas and of the primary metaphors Absence of Light / Darkness and Coldness. The conceptual metaphors integrated the most important information about distress and its experiencer depicted in English media discourse. The most frequent distress metaphors are as follows: EXPERIENCING DISTRESS IS BEING BRITTLE (9 correspondences) - the Container Schema, BEING IN DISTRESS IS BEING DOWN (4) - the Verticality Schema, BEING IN DISTRESS IS BEING IN THE CENTRE (4) - the Centre-Periphery Schema, DISTRESS IS A PHYSICAL OBJECT (4), DISTRESS IS A CONTAINER (3) - the Container Schema. The findings within the most frequently evoked metaphors and 
image schemas can be represented by the prototypical scenario "cause - emotion reaction" (Kövecses, 2003). A severe physical or emotional injury affecting an experiencer stands for the cause of distress which is characterized by being viral and intense. While experiencing distress, a person feels weakness, uncertainty and pressure, and becomes apt to losing inner peace of mind, mental stability, and appropriateness of behaviour. S/he feels desolation, emptiness, and an inability to socialize with other people. Loss of control over his/her feelings and actions, refraining from utterance, a high level of expressiveness, and a pursuit of overcoming, alleviating or outputting/releasing negative emotion are the typical reactions to the situation of distress. The experiencer's intense suffering can lead to mental disorders and problems with health. The prototypical scenario is enriched with the new meanings that arise in media discourse and are conceptualized in image metaphors of distress.

With all the findings, the current study needs to be further developed. The prospects touch upon the investigation of various patterns of metaphor-metonymy interaction for distress and their implementation in mass communication.

\section{References}

BARCELONA, A., 1986. On the concept of depression in American English: A cognitive approach. Revista Canaria de Estudios Ingleses, no. 12, pp. 7-35.

CASASANTO, D. and DIJKSTRA, K., 2010. Motor action and emotional memory. Cognition, vol. 115 , no. 1 , pp. 179-185.

CROFT, W., 2003. The role of domains in the interpretation of metaphors and metonymies. In: R. Dirven and R. Pörings, eds. Metaphor and metonymy in comparison and contrast. Berlin and New York: Mouton de Gruyter, pp. 161-207.

DANCYGIER, B. and SWEETSER, E., 2014. Figurative language. New York: Cambridge University Press.

DING F., 2012. The interaction between metaphor and metonymy in emotion category. In: Theory and practice in language studies. Finland: Academy Publisher, vol. 2, no. 11, pp. 2384-2397.

DIRVEN, R., 2003. Introduction. In: R. Dirven, R. Pörings, eds. Metaphor and metonymy in comparison and contrast. Berlin and New York: Mouton de Gruyter, pp. 1-41.

EKMAN, P., 1973. Darwin and facial expression: A century of research in review. New York: Academic Press, $273 \mathrm{p}$.

FORCEVILLE, C. J. and RENCKENS, T., 2013. The 'good is light' and 'bad is dark' metaphor in feature films. In: Metaphor and the social world. Amsterdam Center for Language and Communication (ACLC).

Available at: http://dare.uva.nl/document/2/136781

GEERAERTS, D., 2002. The interaction of metaphor and metonymy in composite expressions. In: R. Dirven and R. Pörings, eds. Metaphor and metonymy in comparison and contrast. Berlin: Mouton de Gruyter, pp. 435-465.

GRADY, J., 1999. A typology of motivation for conceptual metaphor. In: R. Gibbs and G. Steen, eds. Metaphor in cognitive linguistics. Amsterdam, The Netherlands: John Benjamins, pp. 79-100.

HAMPE, B., 2005. Image schemas in cognitive linguistics: Introduction. In: B. Hampe, ed. From perception to meaning: Image schemas in cognitive linguistics. Berlin: Mouton de Gruyter, pp. 1-12.

HANDL, S., 2011. The conventionality of figurative language: A usage-based study. Tübingen: Gunter Narr Verlag.

IZARD, C. E., 1991. The psychology of emotions. New York: Plenum.

JOHNSON, M., 1987. The body in the mind: The bodily basis of meaning, imagination, and reason. Chicago: Chicago University Press.

KING, Ph., 2012. Metaphor and methodology for cross-cultural investigation of Hebrew emotions. Journal of Translation, vol. 8, no. 1, pp. 9-24.

KRZESZOWSKI, T., 1993. The axiological parameter in preconceptual image schemata. In: R. Geiger and B. Rudzka-Ostyn, eds. Conceptualizations and mental processing in language. Berlin: Mouton de Gruyter, pp. 307-329.

KÖVECSES, Z., 2000. Metaphor and emotion: Language, culture, and body in human feeling. Cambridge: Cambridge University Press. 
KÖVECSES, Z., 2002. Metaphor. A practical introduction. New York: Oxford University Press. KÖVECSES, Z., PALMER, G. B., DIRVEN, R., 2003. Language and emotion: The interplay of conceptualization with physiology and culture. In: R. Dirven and R. Pörings, eds. Metaphor and metonymy in comparison and contrast. Berlin and New York: Mouton de Gruyter, pp. 133-161.

LAKOFF, G. and JOHNSON, M., 1980. Metaphors we live by. Chicago: University of Chicago Press.

LAKOFF, G. and TURNER, M., 1989. More than cool reason: A field guide to poetic metaphor. Chicago: Chicago University Press.

LAKOFF, G., 1987. Women, fire, and dangerous things. Chicago: University of Chicago Press. LAKOFF, G., 1992. Contemporary theory of metaphor.

Available at: http://comphacker.org/comp/engl338/files/2014/02/A9R913D.pdf

LUTZ, C. A., 1988. Unnatural emotions: Everyday sentiments on a Micronesian atoll and their challenge to western theory. Chicago: University of Chicago Press.

MINSKY, M. 2006. The emotion machine: Commonsense thinking, artificial intelligence, and the future of the human mind. New York: Simon \& Schuster.

OGARKOVA, A., SORIANO, C., 2015. Metaphorical profiles of ANGER nouns in three languages: Converging evidence with cross-cultural emotion psychology. Paper presented at Bi-Annual Conference of the International Society for Research on Emotion. Geneve, Switzerland, July 8-10.

OATLEY, K., JOHNSON-LAIRD P. N., 2013. Cognitive approaches to emotions. Trends in Cognitive Sciences, vol.18, no.3, pp.1-7.

Available at: mentalmodels.princeton.edu/papers/2014tics-emotions.pdf

ORTONY, A., CLORE, G. L., COLLINS, A., 1988. The cognitive structure of emotions. UK, Cambridge: Cambridge University Press.

RADDEN, G., 2000. How metonymic are metaphors? In: A. Barcelona, ed. Metaphor and metonymy at the crossroads: A cognitive perspective. Berlin and New York: Mouton de Gruyter, pp. 93-108.

SELYE, H., 1974. Stress without distress. Philadelphia; New York: Lippincott Williams \& Wilkins; 1 st edition.

STEFANOWITSCH, A., 2004. HAPPINESS in English and German: A metaphorical-pattern analysis. In: M. Archad and S. Kemmer, eds. Language, culture, and mind. Stanford: University of Stanford, pp. 137-49.

STOTT, R., MANSELL, W., SALKOVSKIS, P., LAVENDER, A., CARTWRIGHT-HATTON, S., 2010. Oxford guide to metaphors in CBT: Building cognitive bridges (Oxford guides to cognitive behavioural therapy). Oxford University Press, $1^{\text {st }}$ edition.

SWALLOW, D., 20 February 2010. Meaning of colours across cultures. In: Cross-cultural communication, cross-cultural differences, general, other interesting stuff.

Available at: http://www.deborahswallow.com/2010/02/20/meaning-of-colours-acrosscultures/

TALMY, L., 2000. Toward a cognitive semantics: Concept structuring system. Cambridge, Massachusetts: The MIT Press, vol. 1.

Available at: http://wings.buffalo.edu/linguistics/people/faculty/talmy/talmyweb/TCS.html TOMKINS, S. S., 1963. Affect imagery consciousness: Vol. II. The negative affects. New York: Springer.

TOMKINS, S. S., 1984. Affect theory. In: K. R. Scherer and P. Ekman, eds. Approaches to emotion. Hillsdale, NJ: Erlbaum, pp. 163-195.

UNGERER, F., SCHMID, H.J., 2006. An introduction to cognitive linguistics. New York: Pearson Education.

WIERZBICKA, A., 1999. Emotions across languages and cultures: Diversity and universals. UK, Cambridge: Cambridge University Press.

Internet sources:

Boundless, 2016. Somatosensation: Pressure, Temperature, and Pain. In: Boundless Psychology.

Available at: https://www.boundless.com/psychology/textbooks/boundless-psychologytextbook/sensation-and-perception-5/sensory-processes-38/somatosensation-pressuretemperature-and-pain-165-12700/

Bouchez, C. 10 Signs of an Ailing Mind. 
Available at: http://www.webmd.com/mental-health/features/10-signs-ailing-mind\#2 Common Signs of Distress. The University of Melbourne: Counselling and Psychological Services.

Available at: http://services.unimelb.edu.au/counsel/community/staff/sar/distress

Cambridge Dictionary.

Available at: http://dictionary.cambridge.org/

Collins English Dictionary.

Available at: http://www.collinsdictionary.com/dictionary/english

English Oxford Living Dictionary.

Available at: http://www.oxforddictionaries.com/

Longman Dictionary of Contemporary English (LDOCE).

Available at: http://www.Idoceonline.com/

Merriam-Webster's Learner's Dictionary.

Available at: http://learnersdictionary.com/

National Geographic.

Available at: http://www.nationalgeographic.com/

The free dictionary.

Available at: http://www.thefreedictionary.com/

\section{Author's address and contact details}

Anna Verbytska, PhD. student (for Kandydat Nauk)

Faculty of Foreign Philology

The Conversational English Department

4302513 Volya Avenue

Lutsk

Ukraine

Orcid ID: https://orcid.org/0000-0002-4462-9738

E-mail: verbytska.anna@eenu.edu.ua 